\title{
Effect of Tetrodotoxin Pellets in a Rat Model of Postherpetic Neuralgia
}

\author{
Bihong Hong ${ }^{1,2, *}$, Jipeng Sun ${ }^{2}$, Hongzhi Zheng ${ }^{3}$, Qingqing Le ${ }^{2}$, Changsen Wang ${ }^{2,4}$, \\ Kaikai Bai ${ }^{2}$, Jianlin $\mathrm{He}^{2}$, Huanghuang $\mathrm{He}^{2}$ and Yanming Dong ${ }^{1, *}$ \\ 1 Department of Materials Science and Engineering, College of Materials, Xiamen University, \\ Xiamen 361005, China \\ 2 Engineering Research Center of Marine Biological Resource Comprehensive Utilization, Third Institute of \\ Oceanography, State Oceanic Administration, Xiamen 361005, China; jpsun@tio.org.cn (J.S.); \\ qingqingle@163.com (Q.L.); w1277027075@163.com (C.W.); kkbai@tio.org.cn (K.B.); jlhe@tio.org.cn (J.H.); \\ 18259221714@163.com (H.H.) \\ 3 School of pharmaceutical Sciences, Xiamen University, Xiamen 361102, China; \\ 32320171153272@stu.xmu.edu.cn \\ 4 College of Chemical Engineering, Huaqiao University, Xiamen 361021, China \\ * Correspondences: bhhong@tio.org.cn (B.H.); ymdong@xmu.edu.cn (Y.D.); Tel.: +86-592-219-5265 (B.H.); \\ +86-592-218-5106 (Y.D.)
}

Received: 5 May 2018; Accepted: 1 June 2018; Published: 5 June 2018

\begin{abstract}
Postherpetic neuralgia (PHN) is nerve pain caused by a reactivation of the varicella zoster virus. Medications are used to reduce PHN but their use is limited by serious side effects. Tetrodotoxin (TTX) is a latent neurotoxin that can block neuropathic pain, but its therapeutic index is only 3-5 times with intravenous or intramuscular injection. Therefore, we prepared oral TTX pellets and examined their effect in a rat model of PHN induced by resiniferatoxin (RTX). Oral TTX pellets were significantly effective at preventing RTX-induced mechanical and thermal allodynia, and similar to pregabalin. Moreover, oral administration of TTX pellets dose-dependently inhibited RTX-induced PHN compared with intramuscular administration of TTX injection. We also studied the pharmacokinetic profile of TTX pellets. Our results showed that the blood concentration of TTX reached a maximum plasma concentration $\left(\mathrm{C}_{\max }\right)$ at around $2 \mathrm{~h}$, with an elimination half-life time $\left(\mathrm{t}_{1 / 2}\right)$ of $3.23 \pm 1.74 \mathrm{~h}$ after intragastric administration. The median lethal dose $\left(\mathrm{LD}_{50}\right)$ of TTX pellets was $517.43 \mu \mathrm{g} / \mathrm{kg}$ via oral administration to rats, while the median effective dose (ED50) was approximately $5.85 \mu \mathrm{g} / \mathrm{kg}$, and the therapeutic index was 88.45. Altogether, this has indicated that oral TTX pellets greatly enhance safety when compared with TTX injection.
\end{abstract}

Keywords: postherpetic neuralgia; tetrodotoxin; TTX pellets; pharmacokinetics; varicella-zoster virus

\section{Introduction}

Varicella-zoster virus (VZV) is a neurotropic herpes virus. Infection by VZV usually triggers varicella, although VZV can become latent in cranial nerves and the dorsal root along the entire neuraxis, including autonomic ganglia [1]. Based on VZV gene expression [2], two severe complications of VZV infection have been shown: vasculopathy and postherpetic neuralgia (PHN). PHN is defined as severe pain occurring 1 month after rash onset or which persists for greater than 3 months [3]. Incidence of PHN among patients who have had herpes zoster may be as high as 10-35\% [4]. PHN causes impaired activity including sleep disturbances, depression, and social withdrawal, which patients may suffer for years and consequently has a major influence on quality of life [5]. Currently, treatments for PHN include pharmacological therapy and minimally invasive treatments (e.g., nerve block and surgery). Traditional therapeutic drugs include anticonvulsants, opioids, tricyclic antidepressants, 
and non-steroidal anti-inflammatory drugs, which can relieve neuropathic pain [6]. Capsaicin or topical anesthetics (e.g., lidocaine gel) are used for mild pain. Gabapentin and pregabalin are oral anticonvulsant medications, while tricyclic antidepressants reduce PHN pain. These drugs may control the affected person's symptoms but there is no well-established PHN modifying treatment. Further, the efficacy of these traditional drugs is often limited both in amplitude and duration, and their use is frequently associated with side effects that significantly impair quality of life for patients [7]. Tetrodotoxin (TTX) is a latent neurotoxin that can block voltage-gated sodium channels in nerves with a high degree of selectivity [8]. Indeed, a few studies have reported that TTX can suppress action potentials in axons and reduce ectopic peripheral nerve activity, which may block neuropathic pain with minimal side effects at low doses [9]. Importantly, although TTX dosages of 0.1 and $0.3 \mu \mathrm{g}$ produced a small, albeit significant, decrease in mechanical nociceptive threshold, TTX at $1 \mu \mathrm{g}$ did not show a significant change. Furthermore, no gross motor or behavioral side effects were reported after intramuscular (i.m.) administration of $1 \mu \mathrm{g}$ TTX [10].

Pellets are the most commonly used drug form for their distinct advantages, such as controlled drug release, reduced local concentration, increased gastrointestinal transit time, and lower risk of dose dumping compared with tablets. TTX can improve the local anesthesia time of bupivacaine dexamethasone pellets with no in vitro cell toxicity or cell death [11]. Specifically, $0.05 \% w / w$ of TTX extended local anesthesia time from $31.3 \mathrm{~h}$ to $221.7 \mathrm{~h}$ when added to bupivacaine dexamethasone pellets. However, the potential application of TTX may be limited by toxicity, as $0.1 \% w / w$ TTX causes death in all animals [12].

At present, there are three models for evaluating the curative effects of PHN: VZV [13], herpes simplex virus [14], and resiniferatoxin (RTX) [15]. Based on the strong feasibility of RTX and its possible mimic of the PHN-like symptoms, we decided to use RTX to simulate PHN.

Here, based on analgesia of TTX and the advantage of pellets, oral TTX pellets were prepared. Next, we compared the effect of TTX pellets and TTX injection using a rat model of PHN induced by RTX. We also examined the median lethal dose $\left(\mathrm{LD}_{50}\right)$ and pharmacokinetics of the TTX pellets. Our findings indicate that oral TTX pellets greatly enhance safety compared with TTX injection.

\section{Results}

\subsection{Uniformity of TTX Pellets Content}

The preparation of TTX pellets is described in Materials and Methods. The content of TTX in the pellets was enough to be determined by the HPLC-FLD method, as described in Materials and Methods. The HPLC-FLD method showed a good linearity in a TTX concentration range of $0.1024-10.24 \mu \mathrm{g} / \mathrm{mL}$, with $0.1024 \mu \mathrm{g} / \mathrm{mL}$ of the lower limit of quantification (LLOQ) and $0.05 \mu \mathrm{g} / \mathrm{mL}$ of the limit of detection (LOD). The recovery of TTX was $98.07 \% \pm 0.94 \%, 100.99 \% \pm 0.25 \%$, and $99.95 \% \pm 0.55 \%(n=3)$ at the $4.04,4.92$, and $3.00 \mu \mathrm{g} / \mathrm{mL}$ of concentration, respectively. The results showing uniformity of TTX pellets content are shown in Table 1 . Average content $>99 \%$ and relative standard deviation (RSD) of $1.83 \%$, indicate homogeneous pellets content.

Table 1. Uniformity of tetrodotoxin pellets content (batch 2).

\begin{tabular}{cccc}
\hline Sample & Content (\%) & Average Content (\%) & RSD (\%) \\
\hline 1 & 97.02 & & \\
2 & 97.97 & & \\
3 & 99.42 & & \\
4 & 100.02 & & \\
5 & 97.11 & 99.21 & \\
6 & 99.78 & & \\
7 & 102.20 & & \\
8 & 97.16 & & \\
9 & 101.06 & & \\
10 & 100.33 & & \\
\hline
\end{tabular}




\subsection{Percentage of TTX Pellets Released In Vitro}

Preparation of the three batches of TTX pellets were as described in the Materials and Methods. The amount of TTX released from the TTX pellets was enough to be determined by the HPLC-FLD method. The HPLC-FLD method showed a good linearity in a TTX concentration range of $0.5005-12.024 \mu \mathrm{g} / \mathrm{mL}$, with $0.5005 \mu \mathrm{g} / \mathrm{mL}$ of LLOQ and $0.26 \mu \mathrm{g} / \mathrm{mL}$ of LOD. The recovery of TTX was $100.03 \% \pm 0.46 \%, 99.67 \% \pm 0.70 \%$, and $100.50 \% \pm 0.37 \%(n=3)$ at the $4.00,4.95$, and $5.95 \mu \mathrm{g} / \mathrm{mL}$, respectively. As shown in Figure 1, the percentage of main drug release was approximately $90 \%$ over $30 \mathrm{~min}$. With increasing time, the percentage of TTX release improved up to $98 \%$ in $120 \mathrm{~min}$. After this, there were no significant difference with any of the three batches.

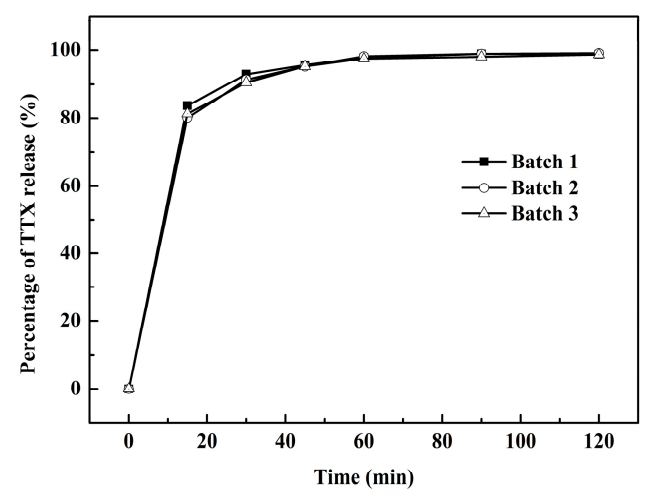

Figure 1. Percentage of tetrodotoxin (TTX) release in vitro.

\subsection{Effect of TTX Pellets in a RTX-Induced Rat Model}

\subsubsection{Effect of RTX on Mechanical and Thermal Allodynia}

The effect of administration of RTX $(200 \mu \mathrm{g} / \mathrm{kg})$ on mechanical pain (Figure 2A) and thermal allodynia (Figure 2B) was examined. Prior to treatment, the mechanical withdrawal threshold was measured using von Frey filaments [16] was $27 \mathrm{~g}(n=20)$. However, within 3 days, the mechanical threshold decreased significantly $(p<0.05)$ in all RTX-injected rats compared with vehicle-treated rats (Figure 2A). Meanwhile, paw withdrawal latency to heat stimulus increased significantly within 6 days $(p<0.001)$ in RTX-injected rats (Figure 2B). Both changes lasted for the duration of the experiment in all rats.

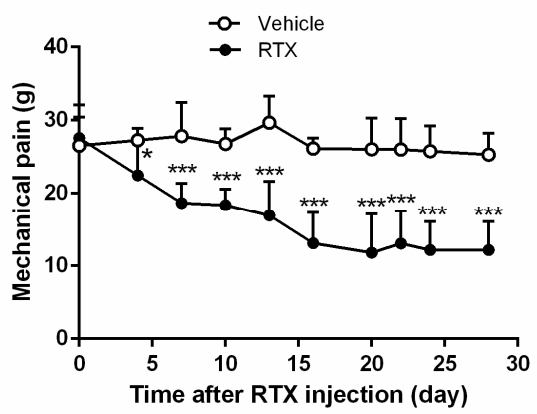

(A)

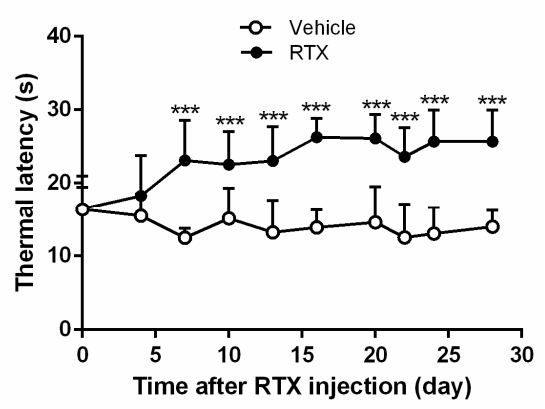

(B)

Figure 2. Time course of the effect of resiniferatoxin on mechanical and thermal allodynia. Time course of the mechanical withdrawal threshold in response to the von Frey filaments in vehicle- and resiniferatoxin (RTX)-treated rats (A); Time course of paw withdrawal latency to a noxious heat stimulus in vehicle- and RTX-injected rats (B). Data are expressed as mean $\pm \operatorname{SD}(n=10$ rats in each group). ${ }^{*} p<0.05$ and ${ }^{* * *} p<0.001$ compared with the vehicle group. 


\subsubsection{Effect of TTX Pellets on Mechanical and Thermal Allodynia Induced by RTX}

The mechanical withdrawal threshold results are shown in Figure 3A. Seven days after the RTX injection, the mechanical withdrawal threshold increased markedly upon first administration of TTX and pregabalin. Subsequently, the mechanical withdrawal threshold decreased after TTX and pregabalin injection until the 12th or 13th day. After this, efficacy improved and was lower than the original mechanical pain.

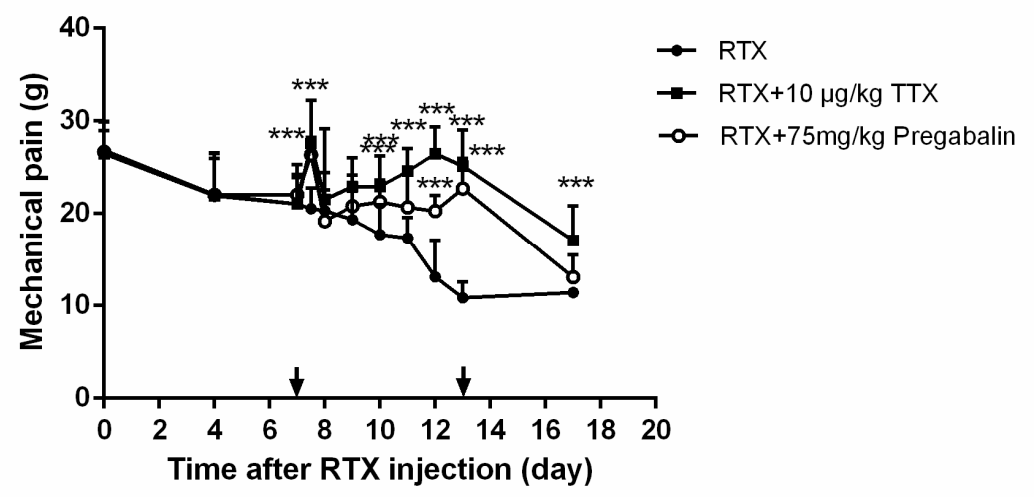

(A)

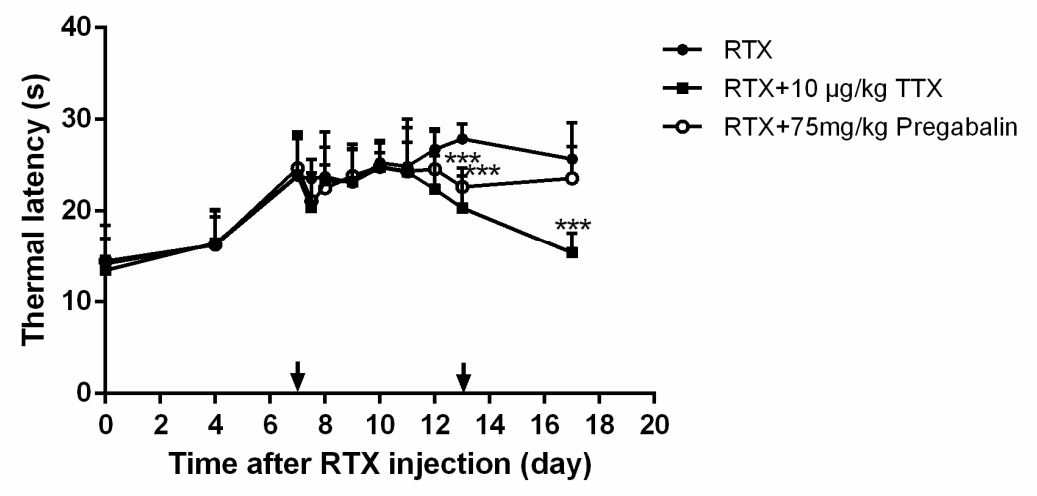

(B)

Figure 3. Time course of the effect of tetrodotoxin on resiniferatoxin-induced mechanical (A) and thermal (B) allodynia. Tetrodotoxin $(10 \mu \mathrm{g} / \mathrm{kg})$, in parallel, pregabalin $(75 \mathrm{mg} / \mathrm{kg})$ were intragastrically administered once a daily for 7 days starting from the 7 th day after resiniferatoxin injection, as indicated. Withdrawal was observed from the 7th to 17th day. Mechanical withdrawal and thermal pain thresholds were detected at $1 \mathrm{~h}$ after TTX or pregabalin administration. Data are expressed as mean $\pm \mathrm{SD}(n=10)$. *** $p<0.001$ compared with the RTX group.

Conversely, there was an obvious reduction in thermal latency by the 7th day after TTX or pregabalin administration (Figure 3B). The effect of both TTX and pregabalin on thermal-increased remission was not observed before 11 days. After that, TTX showed higher efficacy on thermal latency than pregabalin, which may be due to the insensitivity of RTX to thermal latency.

\subsubsection{Effect of TTX Pellets at Different Doses on Mechanical Allodynia}

To determine the effect of the TTX dosage on mechanical pain, rats were treated orally with various doses of TTX or pregabalin $(75 \mathrm{mg} / \mathrm{kg}$, an appropriated dosage chosen by the preliminary test with 300, 150 and $75 \mathrm{mg} / \mathrm{kg}$.) (Figure 4). Both groups were intragastrically (i.g.) administered the drugs daily for 4 days, starting from the 7th day after RTX injection. Compared with the model group, TTX-treated rats showed a significant increase in mechanical pain response in a dose-dependent 
manner. In addition, a high dose of TTX $(20 \mu \mathrm{g} / \mathrm{kg})$ was enough to completely abolish the pain response, and pregabalin showed a similar effect at the $75 \mathrm{mg} / \mathrm{kg}$. The median effective dose (ED50) of the oral TTX pellets was $5.85 \mu \mathrm{g} / \mathrm{kg}$, as calculated by the logit method.

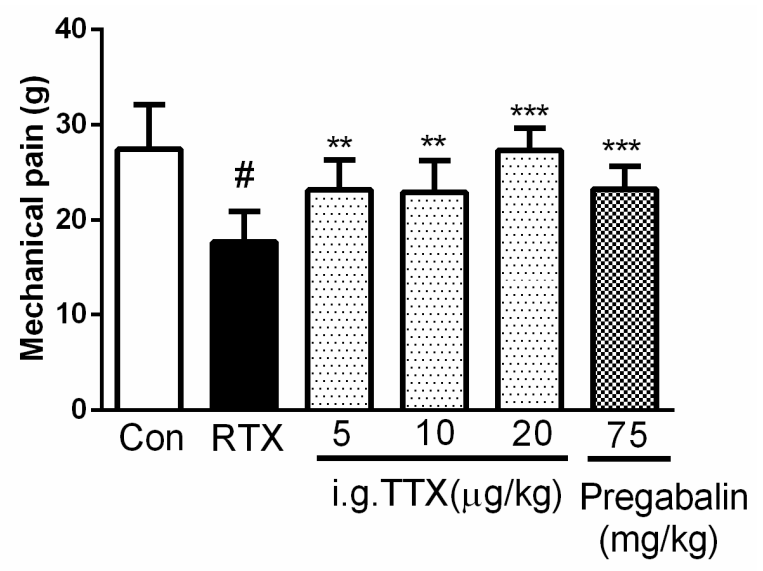

Figure 4. Dose response of oral tetrodotoxin on resiniferatoxin-induced mechanical allodynia. TTX was administered orally daily at doses of 5, 10, and $20 \mu \mathrm{g} / \mathrm{kg}$ for 4 days, starting from the 7 th day after resiniferatoxin (RTX) injection. Pregabalin $(75 \mathrm{mg} / \mathrm{kg}$ ) was administered within the same time frame as TTX. Mechanical pain was detected at $1 \mathrm{~h}$ after TTX or pregabalin. Data are expressed as mean $\pm \mathrm{SD}(n=10) .{ }^{* *} p<0.01,{ }^{* * *} p<0.001$ compared with the RTX group; ${ }^{*} p<0.05$ compared with the control group.

\subsubsection{Effect of TTX Pellets and TTX Injection on Mechanical Allodynia}

Next, we compared the effect of the TTX pellets and TTX injection on their ability to prevent mechanical allodynia induced by RTX. As mentioned, rats were administered TTX daily for 4 days, starting from the 7th day after RTX injection. This also showed a significant increase in mechanical pain response in a dose-dependent manner. Further, TTX-oral $(20 \mu \mathrm{g} / \mathrm{kg})$ administration of the pellets (Figure 4) showed similar effect to that of the high dose of TTX-intramuscular injection $(6 \mu \mathrm{g} / \mathrm{kg}$ )(Figure 5). TTX at $1 \mu \mathrm{g} / \mathrm{kg}$ and $3 \mu \mathrm{g} / \mathrm{kg}$ had no obvious effect on mechanical allodynia. ED50 of TTX injection was $2.49 \mu \mathrm{g} / \mathrm{kg}$, as calculated by the logit method.

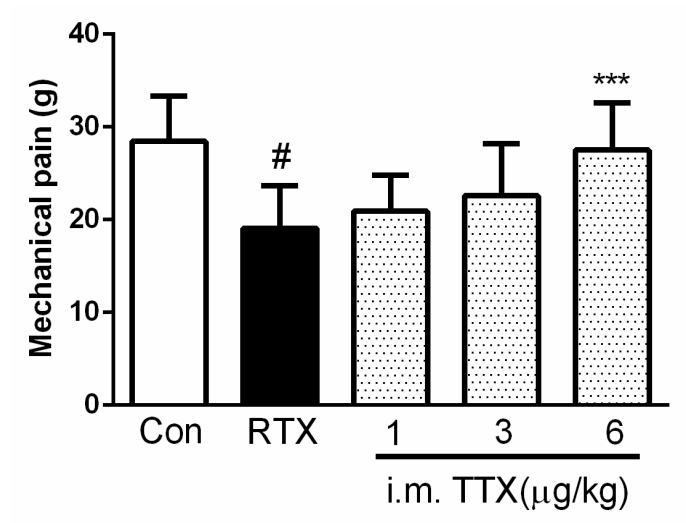

Figure 5. Dose response of intramuscular injection of tetrodotoxin on resiniferatoxin (RTX) -induced mechanical allodynia. TTX was injected daily for 4 days, starting from the 7th day after RTX injection. Mechanical pain was detected at $1 \mathrm{~h}$ after TTX injection. Data are expressed as mean $\pm \operatorname{SD}(n=10)$. ${ }^{* * *} p<0.001$ compared with the RTX group; ${ }^{\#} p<0.05$ compared with the control group. 


\subsection{Acute Toxicity of TTX Pellets}

Rats treated with $692 \mu \mathrm{g} / \mathrm{kg}$ and $814 \mu \mathrm{g} / \mathrm{kg}$ oral TTX pellets showed visibly less movement as well as wheezing and sluggishness. Death initially occurred at 8-10 min after administration. However, most death occurred within 2-6 h but up until $10 \mathrm{~h}$, after which there was no more death. There were no obvious changes in the gross anatomy of the dead animals. As shown in Table 2, $\mathrm{LD}_{50}$ was $517.43 \mu \mathrm{g} / \mathrm{kg}$, as calculated by the Bliss method, with a $95 \%$ confidence limit of $459.41-582.79 \mu \mathrm{g} / \mathrm{kg}$. $\mathrm{LD}_{50}$ for female rats was $441.2 \mu \mathrm{g} / \mathrm{kg}$, while for male rats was $573.95 \mu \mathrm{g} / \mathrm{kg}$.

Table 2. Acute toxicity test showing death after a single oral administration of tetrodotoxin pellets to Sprague-Dawley rats.

\begin{tabular}{cccc}
\hline Dose $(\boldsymbol{\mu g} / \mathbf{k g})$ & $\uparrow$ & $\sigma^{\top}$ & Death \\
\hline 814 & $4 / 5$ & $4 / 5$ & $8 / 10$ \\
692 & $3 / 5$ & $3 / 5$ & $6 / 10$ \\
588 & $4 / 5$ & $2 / 5$ & $6 / 10$ \\
500 & $3 / 5$ & $3 / 5$ & $6 / 10$ \\
425 & $2 / 5$ & $1 / 5$ & $3 / 10$ \\
Total & $16 / 25$ & $13 / 25$ & $29 / 50$ \\
LD 50 & 441.2 & 573.95 & 517.43 \\
\hline
\end{tabular}

Body weight changes in Sprague-Dawley rats following a single oral administration of TTX pellets are shown in Table 3. The distribution of animal weight before the drug administration was average. No significant differences were found with increasing weight of the rats.

Table 3. Body weight changes of Sprague-Dawley rats after single oral administration of tetrodotoxin pellets.

\begin{tabular}{|c|c|c|c|}
\hline \multirow{2}{*}{ Dose $(\mu \mathrm{g} / \mathrm{kg})$} & \multirow{2}{*}{ Gender } & \multicolumn{2}{|c|}{ Body Weight } \\
\hline & & 0 Day & 7 Day \\
\hline \multirow{2}{*}{814} & $\sigma^{x}$ & $197.6 \pm 5.03$ & $247(n=1)$ \\
\hline & ㅇ & $188.4 \pm 7.47$ & $196(n=1)$ \\
\hline \multirow{2}{*}{692} & $0^{x}$ & $189.2 \pm 10.62$ & $230 \pm 16.97(n=2)$ \\
\hline & o & $189.8 \pm 6.30$ & $202 \pm 5.66(n=2)$ \\
\hline \multirow{2}{*}{588} & $\sigma^{x}$ & $184.8 \pm 4.60$ & $237 \pm 10.82(n=3)$ \\
\hline & q & $193.0 \pm 9.17$ & $215(n=1)$ \\
\hline \multirow{2}{*}{500} & $\sigma^{\pi}$ & $188.8 \pm 8.56$ & $226.5 \pm 7.78(n=2)$ \\
\hline & q & $190.8 \pm 9.58$ & $199 \pm 6.74(n=2)$ \\
\hline \multirow{2}{*}{425} & $\sigma^{\pi}$ & $193.6 \pm 6.54$ & $250 \pm 7.21(n=4)$ \\
\hline & q & $187.2 \pm 4.60$ & $\begin{array}{c}201.5 \pm 13.44(n= \\
3)\end{array}$ \\
\hline
\end{tabular}

\subsection{Pharmacokinetics Following Intragastric TTX Pellets Administration}

\subsubsection{TTX Injection}

The content of TTX in the blood of tested rats could only be determined by the UPLC-MS/MS method, instead of the HPLC-FLD method used for the determination of the university of TTX pellets and the release of TTX from the pellets, because of the lower level of TTX in the rat blood. The UPLC-MS/MS method showed a good linearity in a TTX concentration range of $0.02-2.00 \mathrm{ng} / \mathrm{mL}$, with $0.02 \mathrm{ng} / \mathrm{mL}$ of LLOQ and $0.009 \mathrm{ng} / \mathrm{mL}$ of LOD. The recovery of TTX was $97.10 \% \pm 4.52 \%$, $92.80 \% \pm 3.53 \%$, and $103.00 \% \pm 6.89 \%(n=3)$ at the $0.04,0.40$, and $1.60 \mathrm{ng} / \mathrm{mL}$, respectively. 
The time course of TTX concentration in the blood of rats after intravenous (i.v.) injection at a dose of $6 \mu \mathrm{g} / \mathrm{kg}$ is shown in Figure 6. The blood concentration of TTX was $4.12 \mathrm{ng} / \mathrm{mL}$ at $0.08 \mathrm{~h}$ after administration and then declined gradually.

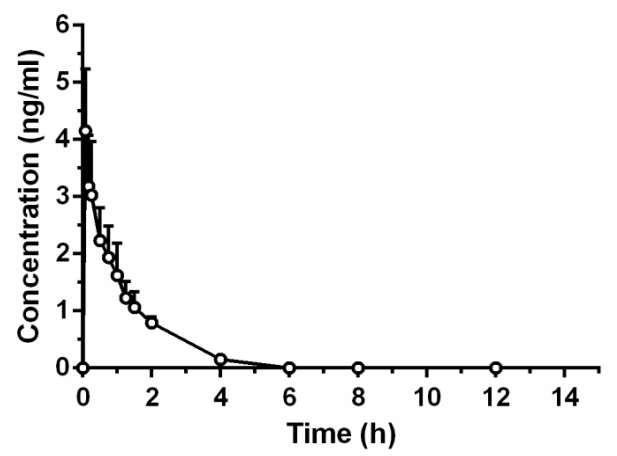

Figure 6. Mean concentration-time profile of tetrodotoxin in rat plasma following intravenous administration at a dose of $6 \mu \mathrm{g} / \mathrm{kg}$.

The pharmacokinetic parameters are summarized in Table 4. After i.v. injection, the mean value for systemic clearance (CL) was $1349.40 \pm 326.75 \mathrm{~mL} / \mathrm{h} / \mathrm{kg}$, with an elimination half-life time $\left(\mathrm{t}_{1 / 2}\right)$ of $0.92 \pm 0.17 \mathrm{~h}$. The area under the plasma concentration-time curve from zero to the end time point $\left(\mathrm{AUC}_{0-\mathrm{t}}\right)$ and area under the plasma concentration-time curve from zero to infinity $\left(\mathrm{AUC}_{0-\infty}\right)$ was $4.42 \pm 0.90 \mathrm{ng} \cdot \mathrm{h} / \mathrm{mL}$ and $4.63 \pm 0.90 \mathrm{ng} \cdot \mathrm{h} / \mathrm{mL}$, respectively, while the apparent volume of distribution (Vd) was $1824.68 \pm 709.84 \mathrm{~mL} / \mathrm{kg}$.

Table 4. Pharmacokinetic parameters of tetrodotoxin in rat plasma samples after intravenous administration.

\begin{tabular}{ccc}
\hline Parameters & Unit & Intravenous Tetrodotoxin of $\mathbf{6} \boldsymbol{\mu g} / \mathbf{k g}$ \\
\hline $\mathbf{A U C}_{\mathbf{0 - t}}$ & $\mathrm{ng} \cdot \mathrm{h} / \mathrm{mL}$ & $4.42 \pm 0.90$ \\
$\mathbf{A U C}_{\mathbf{0}-\boldsymbol{\infty}}$ & $\mathrm{ng} \cdot \mathrm{h} / \mathrm{mL}$ & $4.63 \pm 0.90$ \\
$\mathbf{t}_{\mathbf{1} / \mathbf{2}}$ & $\mathrm{h}$ & $0.92 \pm 0.17$ \\
$\mathbf{C L}$ & $\mathrm{mL} / \mathrm{h} / \mathrm{kg}$ & $1349.40 \pm 326.75$ \\
$\mathbf{V d}$ & $\mathrm{mL} / \mathrm{kg}$ & $1824.68 \pm 709.84$ \\
\hline
\end{tabular}

\subsubsection{Intragastric TTX Pellets}

The pharmacokinetic profile following oral administration of $100 \mu \mathrm{g} / \mathrm{kg}$ (TTX could be better detected in blood) TTX pellets to rats is shown in Figure 7, with the pharmacokinetic parameters listed in Table 5. The blood concentration of TTX increased from $0 \mathrm{ng} / \mathrm{mL}$ to $0.70 \mathrm{ng} / \mathrm{mL}$ within $15 \mathrm{~min}$ after administration. Moreover, plasma concentration increased from $15 \mathrm{~min}$ to $120 \mathrm{~min}$ but the slope declined, after which there was a gradual increase to the peak concentration of $0.93 \pm 0.23 \mathrm{ng} / \mathrm{mL}$ at $2.08 \pm 0.49 \mathrm{~h}$. After this, TTX concentration gradually decreased but was still present at a reasonable concentration compared with i.v. injection.

Following i.g. TTX administration, $\mathrm{AUC}_{0-\mathrm{t}}$ was $4.91 \pm 0.99 \mathrm{ng} \cdot \mathrm{h} / \mathrm{mL}$ while $\mathrm{AUC}_{0-\infty}$ was $5.82 \pm 1.65 \mathrm{ng} \cdot \mathrm{h} / \mathrm{mL}$. Meanwhile, $\mathrm{t}_{1 / 2}$ was $3.23 \pm 1.74 \mathrm{~h}$ with $\mathrm{CL}$ of $18188.62 \pm 4234.34 \mathrm{~mL} / \mathrm{h} / \mathrm{kg}$, showing a long-lasting effect of i.g. administration compared with i.v. injection. Further, $\mathrm{Vd}$ was $76276.28 \pm 22601.44 \mathrm{~mL} / \mathrm{kg}$, indicating centralized organizational distribution following i.g. administration. Compared with i.v. administration of TTX, oral bioavailability of TTX pellets was only $6.7 \%$. 


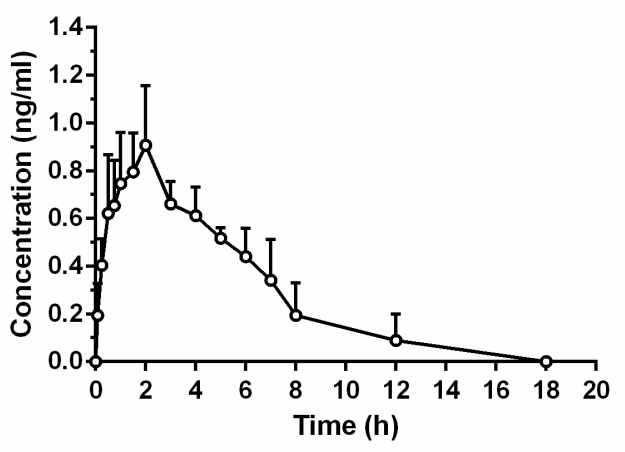

Figure 7. Mean concentration-time profile of tetrodotoxin pellets in rat plasma following intragastric administration at a dose of $100 \mu \mathrm{g} / \mathrm{kg}$.

Table 5. Pharmacokinetic parameters of tetrodotoxin pellets in rat plasma samples after oral administration.

\begin{tabular}{ccc}
\hline Parameters & Unit & Intragastric Tetrodotoxin of $\mathbf{1 0 0} \mathbf{\mu g} / \mathbf{k g}$ \\
\hline $\mathbf{C}_{\max }$ & $\mathrm{ng} / \mathrm{mL}$ & $0.93 \pm 0.23$ \\
$\mathbf{T}_{\max }$ & $\mathrm{h}$ & $2.08 \pm 0.49$ \\
$\mathbf{A U C}_{\mathbf{0 - t}}$ & $\mathrm{ng} \cdot \mathrm{h} / \mathrm{mL}$ & $4.91 \pm 0.99$ \\
$\mathbf{A U C}_{\mathbf{0}-\infty}$ & $\mathrm{ng} \cdot \mathrm{h} / \mathrm{mL}$ & $5.82 \pm 1.65$ \\
$\mathbf{t}_{\mathbf{1} / \mathbf{2}}$ & $\mathrm{h}$ & $3.23 \pm 1.74$ \\
$\mathbf{C L}$ & $\mathrm{mL} / \mathrm{h} / \mathrm{kg}$ & $18,188.62 \pm 4234.34$ \\
$\mathbf{V d}$ & $\mathrm{mL} / \mathrm{kg}$ & $76,276.28 \pm 22,601.44$ \\
$\mathbf{F}$ & & $6.7 \%$ \\
\hline
\end{tabular}

\section{Discussion}

A strongly acidic condition affects the heat stability of TTX. However, TTX is relatively stable in gastric $\mathrm{pH}(1-2)$ around $37^{\circ} \mathrm{C}$. Following oral administration of TTX, $\mathrm{LD}_{50}$ was 38.12-times greater than after i.v. injection, which reflects a considerable decrease in bioavailability following oral administration [17]. Consequently, clinical injection is commonly administered through local muscle. However, although i.m. injection of TTX has a significant effect, the TTX dose is regarded as a crucial safety factor because of the high toxicity of TTX. Acute toxicity symptoms of TTX include central nervous system depression and neuromuscular blockage both locally and systemically. Acute toxicity tests in male and female rats following a single i.m. injection showed $\mathrm{LD}_{50}$ values of 10.53 and $11.75 \mu \mathrm{g} / \mathrm{kg}$, respectively. In addition, the half-life of a muscle injection is short, with TTX only present in the plasma for $2 \mathrm{~h}$. Thus, to maintain drug efficacy, frequent injections are needed, which leads to poor clinical compliance. Accordingly, an oral preparation with an extended therapeutic window (as well as clinical compliance) is necessary for the TTX application.

Subcutaneous injection of TTX has been researched for cancer-related pain. Patients who received $30 \mu \mathrm{g}$ TTX twice daily for 4 consecutive days resulted in an analgesic response of 56.7 days, while the placebo only enabled 9.9 days [18]. There was still a significant anti-hyperalgesia effect at $24 \mathrm{~h}$ with topical injection of 0.03-1.0 $\mathrm{gg} / \mathrm{kg}$ TTX [10]. TTX as an effective treatment at low doses has shown that $1.0-3.0 \mu \mathrm{g} / \mathrm{kg}$ TTX reduces the expression of mechanical allodynia. In contrast, $3.0-6.0 \mu \mathrm{g} / \mathrm{kg}$ TTX had no effect on the same thermal and mechanical stimuli [19].

In this study, we compared different routes of administration. Oral administration showed a flatter change, while efficacy changed rapidly with the increasing concentration of the i.m. injection. This indicates that the oral administration of TTX has a wider and safer dosage range. In addition, $\mathrm{LD}_{50}$ and $\mathrm{ED}_{50}$ of oral administration of TTX pellets were $517.43 \mu \mathrm{g} / \mathrm{kg}$ and $5.85 \mu \mathrm{g} / \mathrm{kg}$, respectively, resulting in a therapeutic index of 88.45 . In contrast, $\mathrm{LD}_{50}$ and $\mathrm{ED}_{50}$ for i.m. administration were approximately $11 \mu \mathrm{g} / \mathrm{kg}$ and $2.49 \mu \mathrm{g} / \mathrm{kg}$, respectively, with a therapeutic index of 4.42 . This further indicates the superior safety of oral administration. Nevertheless, oral administration showed a 
low bioavailability of approximately $6.7 \%$, with high $\mathrm{Vd}$ of $76,276 \mathrm{~mL} / \mathrm{kg}$, reflecting a concentrated distribution. Some studies have reported the higher distribution of TTX in the gastric intestinal wall, lungs, kidney, and heart than in plasma at $0.5 \mathrm{~h}$ after i.m. administration. Meanwhile, TTX has also been shown to be rapidly distributed in the gastrointestinal tract after entering the body [20], suggesting that sodium channels in the gastrointestinal tract are blocked, which likely prolonged the duration of TTX absorption. This may be related to the long-term efficacy of oral administration. In addition, the $\mathrm{LD}_{50}$ for the oral single administration of TTX pellets in the female and male rats was 441.2 and $573.95 \mu \mathrm{g} / \mathrm{kg}$, respectively, while the $\mathrm{LD}_{50}$ for the single intramuscular administration of TTX injections was 10.53 and $11.75 \mu \mathrm{g} / \mathrm{kg}$ in the male and female rats, respectively. This has suggested that the toxicity of TTX was different in females and males, and the females are likely more sensitive to the toxic effect of TTX than the males. The specific reasons for the differences require further detailed investigation in future studies.

To the best of our knowledge, up to date pregabalin and gabapentin were the most valuable medications in clinical use for PHN, however, there were daily episodes of somnolence that typically occurred in $25 \%$ and dizziness that occurred in $46 \%$ at the clinic [21,22]. TTX as an analgesics was applied for various pain in clinical study [23]. TTX, as an analgesic agent against uncontrolled cancer pain has been investigated in a phase III trial by WEX Pharmaceuticals. Furthermore, TTX was also evaluated to treat the neuropathic pain caused by chemotherapy-induced peripheral neuropathy in a phase II trial [24] . The analgesic effect of TTX increased in the 4 or 5th day of administration but decreased in the 10th day. Furthermore, the analgesic effect disappeared from the next week of administration. During the TTX administration, the neurological examination, vital signs, oxygen saturation, clinical chemistry tests, and 12-lead ECG measures were not affected [25]. In these clinical studies, when TTX (30 $\mu \mathrm{g})$ was subcutaneously injected twice daily for continuous 4 days, most side effects were those with mild to moderately severities, such as tingling, numbness or other transient sensory symptoms, but no evidence of cumulative toxicity or tolerability in the long-term. In the present study, the highest dosage of TTX $(20 \mu \mathrm{g} / \mathrm{kg})$ of the pellets was orally administrated to rats once a day for continuous 7 days and no obvious side effects were observed in the test rats. The dosage of TTX $(20 \mu \mathrm{g} / \mathrm{kg})$ in the animal test was equivalent to the dosage of TTX (55.5-222.2 $\mu \mathrm{g} /$ person) in human use. Thus, the result suggested the lower side effects of the oral administration of TTX pellets than the intramuscular or subcutaneous administration of TTX injections.

\section{Materials and Methods}

\subsection{Reagents}

Tetrodotoxin standard (assay 99.2\%) was provided by the Third Institute of Oceanography State Oceanic (Xiamen, China). Tetrodotoxin (assay 98.5\%) and Tetrodotoxin injection (assay $10.1 \mu \mathrm{g} / \mathrm{mL}$ ) were provided by Xiamen Chaoyang Biological Engineering Co., Ltd. (Xiamen, China). RTX was purchased from J\&K Chemical (Shanghai, China). Sugar sphere $(600-710 \mu \mathrm{m})$ was purchased from JRS PHARMA Co., Ltd. (Rosenberg, Germany). Opadry (YS-1-7006) was purchased from Colorcon Co., Ltd. (Shanghai, China). Hydroxypropyl Methylcellulose (HPMC) was purchased from Huzhou Zhanwang Pharmaceutical Co., Ltd. (Huzhou, China). Citric acid was purchased from TaishanXinning Pharmaceutical Co., Ltd. (Taishan, China). 1-Octanesulfonate sodium was provided by Regis Technologies (Morton Grove, IL, USA). Sodium phosphate monobasic dehydrate, sodium phosphate dibasic dehydrate, sodium hydroxide, phosphoric acid, and acetonitrile were provided by Sinopharm Chemical Reagent Co., Ltd. (Shanghai, China). Talc $(10 \mu \mathrm{m})$ was purchased from Guangxi Longsheng Huamei Talc Development Co., Ltd. (Sanmen Town, China). 


\subsection{Animals and Experimental Design}

\subsubsection{Animals}

Experiments were performed using adult Sprague-Dawley rats (220-280 g) purchased from the Experimental Animal Center of Shenyang Pharmaceutical University (Shenyang, China). All procedures were approved by the Animal Care Committee at Shenyang Pharmaceutical University. Rats were acclimatized to the laboratory for at least 3 days before starting experiments. Rats were housed with five per cage on a $12 \mathrm{~h}$ light/dark cycle, with free access to food and water under controlled temperature $\left(20-24{ }^{\circ} \mathrm{C}\right)$ and humidity $(45-65 \%)$. Food and water were allowed ad libitum during the study period.

\subsubsection{Experimental Design for RTX-Induced PHN}

Each rat in the RTX group received a single intraperitoneal injection of RTX $(200 \mu \mathrm{g} / \mathrm{kg})$ under halothane anesthesia (2\% in oxygen). RTX was dissolved in a mixture of $10 \%$ Tween 80 and $10 \%$ ethanol in normal saline. Separate rats received a mixture of $10 \%$ Tween 80 and $10 \%$ ethanol in normal saline and were used as the vehicle control. Before RTX or vehicle treatment, the baseline sensitivity of each rat to mechanical and thermal stimulation was measured.

\subsubsection{Nociceptive Behavioral Tests}

Behavioral tests were performed three times before RTX injection, and once every other day, starting from 1 week after the RTX injection. Animals were habituated to the testing environment for $30 \mathrm{~min}$. Thermal sensitivity was assessed by exposing the mid-plantar surface of the hind paw to a radiant heat beam through a transparent glass surface using a plantar analgesia meter (RWD Life Science Inc., Shenzhen, China). Mean value for withdrawal latency was calculated on two to three consecutive trials. A cutoff of $30 \mathrm{~s}$ was used to avoid potential tissue damage.

Mechanical allodynia was assessed by placing the rats on an elevated mesh floor, with the tactile threshold measured using the "up-down" method [26]. After an acclimation period of $30 \mathrm{~min}$, a series of calibrated von Frey filaments were perpendicularly applied to the plantar surface of both hind paws with sufficient force to bend the filament for $6 \mathrm{~s}$. Brisk withdrawal or paw flinching was considered a positive response. The test was repeated two to three times in each rat, and the mean value calculated.

\subsubsection{Statistical Analysis}

All behavioral data are presented as mean \pm SD. Paw withdrawal threshold or latency and the effect of TTX on the withdrawal threshold were examined by an analysis of variance followed by Tukey's post hoc test. $p<0.05$ was considered statistically significant.

\subsection{TTX Pellets Content}

High-performance liquid chromatography analytical method (HPLC-FLD) [27-32].

High-performance liquid chromatography (HPLC) separation was performed on a Waters 2695 HPLC system (Waters, Milford, MA, USA) using a ZORBAX SB-C8 column (4.6 mm $\times 250 \mathrm{~mm}, 5 \mu \mathrm{m})$. The mobile phase comprised 1-octanesulfonate sodium-phosphate buffer ( $8.95 \mathrm{~g}$ sodium phosphate dibasic dehydrate, $3.90 \mathrm{~g}$ sodium phosphate monobasic dehydrate, and $0.27 \mathrm{~g}$ 1-octanesulfonate sodium dissolved in distilled water up to $500 \mathrm{~mL}$ with stirring and filtrating), with a flow rate of $0.3 \mathrm{~mL} / \mathrm{min}$. The column temperature was maintained at $28^{\circ} \mathrm{C}$ and injected volume was $10 \mu \mathrm{L}$. HPLC was combined with a fluorescence detector (2475; Waters), with intensity monitored using excitation and emission wavelengths of $365 \mathrm{~nm}$ and $510 \mathrm{~nm}$, respectively. The post column reaction (reaction coil: Waters RXN 1000, Volume $1000 \mu \mathrm{L}$, Coil 0.018 inch ID polytetrafluoroethylene tubing knitted) reagent was $4 \mathrm{~mol} / \mathrm{LNaOH}$, injection volume of $10 \mu \mathrm{L}$ at a flow rate of at $0.3 \mathrm{~mL} / \mathrm{min}$, and temperature of $110^{\circ} \mathrm{C}$. 
TTX pellets were accurately weighed and then powdered. The powder was transferred to a $50 \mathrm{~mL}$ volumetric flask. After ultrasonication for $20 \mathrm{~min}$, diluent solution was then cooled, stirred, and filtrated. Filtrate was detected by HPLC. The sample content was calculated using the external standard method [33].

\subsection{Release of TTX Pellets}

The release determination test was performed using the Pharmacopoeia of China (CHP) and U.S. Pharmacopeia (USP) paddle apparatus [34] (RC806D; TiandaTianfa Technology, Tianjin, China), with dissolution medium (water) equilibrated at a rotational speed of $100 \mathrm{r} / \mathrm{min}$ and a temperature of $37 \pm 0.5^{\circ} \mathrm{C}$. Samples of $2 \mathrm{~mL}$ were automatically collected at each time point and $2 \mathrm{~mL}$ fresh dissolution medium replenished. Samples were passed through $0.45 \mu \mathrm{m}$ microporous membrane and filtrates assayed by HPLC to calculate drug content in the medium and percentage of the final release amount [35].

\subsection{Preparation of TTX Pellets}

\subsubsection{Preparation of Drug-Loaded Pellets}

TTX solution of $0.4 \mathrm{mg} / \mathrm{mLwas}$ prepared with $0.1 \%$ citric acid as the assistant-solvent and $0.5 \%$ HPMC as the binder. Drug-loaded pellets were prepared using a bottom spray fluid bed(WBF-5G; Chongqing Enger Granulating \& Coating Technological, Chongqing, China) [36]. Drug-loaded pellets $\left(400 \mathrm{~g}\right.$ ) were used with the following experimental conditions: inlet air temperature of $40{ }^{\circ} \mathrm{C}$, air flow rate at $150 \mathrm{~m}^{3} / \mathrm{h}$, solution temperature at $25-35{ }^{\circ} \mathrm{C}$, atomization pressure at $0.16 \mathrm{MPa}$, and rotating pump speed of $2 \mathrm{r} / \mathrm{min}$. After drug loading was complete, the pellets were dried in the fluid bed for 15 min at $40^{\circ} \mathrm{C}$.

\subsubsection{Preparation of TTX Pellets by Coating}

Drug-loaded pellets ( $380 \mathrm{~g}$ ) were transferred into a fluid bed. The coating solution was prepared with a mixture of $5 \%(w / w) 190 \mathrm{~mL}$ opadry and $4.8 \mathrm{~g}$ talc using an emulsifying homogenizer (EA 200; Shanghai OuHor Mechanical Equipment, Shanghai, China) for $10 \mathrm{~min}$. Next, the coating solution was passed through a $250 \mu \mathrm{m}$ sieve and continuously stirred [37]. The experimental condition parameters for the coating process were the same as for the drug-loaded process. After coating was completed, the pellets were dried in a fluid bed for $15 \mathrm{~min}$ at $40^{\circ} \mathrm{C}$.

\subsection{Pharmacokinetic Studies}

\subsubsection{TTX Administration and Plasma Sample Collection}

For pharmacokinetic studies of the TTX injection, a group of six rats (three males and three females) with jugular vein catheterization were each i.v. administered a TTX injection $(6 \mu \mathrm{g} / \mathrm{kg})$. Serial blood samples $(0.3 \mathrm{~mL})$ were collected in heparinized tubes via the jugular vein before and at time points of $0.08,0.17,0.25,0.5,0.75,1.0,1.25,1.5,2.0,4.0,6.0,8.0$, and $12.0 \mathrm{~h}$ after administration. Plasma was separated and stored frozen at $-20{ }^{\circ} \mathrm{C}$ until analysis.

For pharmacokinetic studies of TTX pellets, a group of six rats (three males and three females) with jugular vein catheterization were each i.g. administered a TTX pellets $(100 \mu \mathrm{g} / \mathrm{kg})$. Serial blood samples $(0.3 \mathrm{~mL})$ were collected in heparinized tubes via the jugular vein before and at time points of $0.08,0.25,0.5,0.75,1.0,1.5,2.0,3.0,4.0,5.0,6.0,7.0,8.0,12.0$, and $18.0 \mathrm{~h}$ after administration. Plasma was separated and stored frozen at $-20^{\circ} \mathrm{C}$ until analysis. 


\subsubsection{Chromatographic and Mass Spectrometric Conditions (UPLC/MS/MS)}

\section{Liquid Chromatography Conditions}

Analyte separations were performed on an Acquity UPLC-1290 system (Agilent Corp., Milford, MA, USA) using a ZIC HILIC column $(2.1 \times 150 \mathrm{~mm}, 5 \mu \mathrm{m})$ equilibrated with $80 \%$ solvent A $(0.04 \%$ ammonium acetate acetonitrile solution) and $20 \%$ solvent $\mathrm{B}(0.04 \%$ ammonium acetate aqueous solution) at a flow rate of $0.4 \mathrm{~mL} / \mathrm{min}$. After $6 \mathrm{~min}$, a linear gradient was run to $40 \%$ solvent over $0.1 \mathrm{~min}$, and maintained for $2 \mathrm{~min}$, followed by a linear gradient to $80 \%$ solvent $\mathrm{A}$.

\section{Mass Spectrometry Conditions}

An analysis of TTX in plasma samples was performed using an AB Q-trap liquid chromatography-tandem mass spectrometry (LC-MS/MS) system (ABSCIEX, Framingham, MA, USA) equipped with electrospray ionization (ESI). Quantitative analysis of TTX was performed in the positive ion mode under the following conditions: ion spray voltage at $3500 \mathrm{~V}, 350^{\circ} \mathrm{C}$, skimmer offset at $11 \mathrm{~V}$, tube lens offset at $140 \mathrm{~V}$, sheath gas pressure at $90 \mathrm{~V}$, auxiliary gas pressure at $10 \mathrm{~V}$, sweep gas flow at $40 \mathrm{~V}$, collision energy at $47 \mathrm{eV}$, and scan type at MRu. AB Analyst 1.6.1 software (ABSCIEX) was used for system control and data acquisition.

\subsubsection{Statistical Analysis}

A pharmacokinetic analysis was performed using drug and statistics software (version 2.0, Mathematical Pharmacology Professional Committee of China, Shanghai, China) to examine key parameters including maximum plasma concentration $\left(\mathrm{C}_{\max }\right)$, time to maximum concentration $\left(\mathrm{T}_{\max }\right)$, $\mathrm{t}_{1 / 2}, \mathrm{AUC}_{0-\mathrm{t}}$, and $\mathrm{AUC}_{0-\infty}$. Oral bioavailability $(\mathrm{F})$ was measured by comparing each AUC value after i.g. and i.v. administration according to the following equation:

$$
\mathrm{F}=\left(\mathrm{AUC}_{\text {i.g. }} / \text { Dose }_{\text {i.g. }}\right) /\left(\mathrm{AUC}_{\text {i.v. }} / \text { Dose }_{\text {i.v. }}\right) \times 100 \%
$$

\section{Conclusions}

In the present study, we examined the effect of TTX pellets in a rat model of PHN. Oral administration of TTX pellets was more effective at preventing RTX-induced mechanical and thermal allodynia than pregabalin or TTX injection. We also determined $\mathrm{LD}_{50}$ after oral administration of TTX pellets to rats, showing that oral TTX pellets greatly enhance safety when compared with TTX injection.

Author Contributions: Conceptualization, B.H. and Y.D.; Formal analysis, J.S., H.Z., Q.L., C.W., K.B. and J.H.; Investigation, B.H., J.S., H.Z. and Q.L.; Writing-original draft, B.H. and H.H.

Acknowledgments: This work was supported financially by the Public Science and Technology Research Funds Projects of Ocean (No. 201405016), Xiamen Southern Oceanographic Center (No. 13GYY001NF05), and The Scientific Research Foundation of the Third Institute of Oceanography, SOA. (No. 2009051).

Conflicts of Interest: The authors declare no conflict of interest.

\section{References}

1. Sadosky, A.; Scd, M.D.; Brandenburg, N.A.; Strauss, M. A review of the epidemiology of painful diabetic peripheral neuropathy, postherpetic neuralgia, and less commonly studied neuropathic pain conditions. Pain Pract. 2008, 8, 45-56. [CrossRef] [PubMed]

2. Gilden, D.H.; Cohrs, R.J.; Mahalingam, R. VZV vasculopathy and postherpetic neuralgia: Progress and perspective on antiviral therapy. Neurology 2005, 64, 21-25. [CrossRef] [PubMed]

3. Schmader, K.E. Epidemiology and impact on quality of life of postherpetic neuralgia and painful diabetic neuropathy. Clin. J. Pain 2002, 18, 350-354. [CrossRef] [PubMed] 
4. Gavin, P.D.; Tremper, L.; Smith, A.; Williams, G.; Brooker, C. Transdermal oxycodone patch for the treatment of postherpetic neuralgia: A randomized, double-blind, controlled trial. Pain Manag. 2017, 7, 255-267. [CrossRef] [PubMed]

5. Dworkin, R.H.; Portenoy, R.K. Pain and its persistence in herpes zoster. Pain 1996, 67, 241-251. [CrossRef]

6. Dworkin, R.H.; Corbin, A.E.; Young, J.P.; Sharma, U.; Lamoreaux, L.; Bockbrader, H.; Garofalo, E.A.; Poole, R.M. Pregabalin for the treatment of postherpetic neuralgia a randomized, placebo-controlled trial. Neurology 2003, 60, 1274-1283. [CrossRef] [PubMed]

7. Ling, W. Prescription opioid addiction and chronic pain: More than a feeling. Drug Alcohol Depend. 2017, 173, S73-S74. [CrossRef] [PubMed]

8. Chen, T.Y.; Hsieh, C.H.; Hwang, D.F. Development of standardized methodology for identifying toxins in clinical samples and fish species associated with tetrodotoxin-borne poisoning incidents. J. Food Drug Anal. 2015, 24, 9-14. [CrossRef] [PubMed]

9. Kayser, V.; Viguier, F.; Ioannidi, M.; Bernard, J.F.; Latrémolière, A.; Michot, B.; Vela, J.M.; Buschmann, H.; Hamon, M.; Bourgoin, S. Differential anti-neuropathic pain effects of tetrodotoxin in sciatic nerve-versus infraorbital nerve-ligated rats-Behavioral, pharmacological and immunohistochemical investigations. Neuropharmacology 2010, 58, 474-487. [CrossRef] [PubMed]

10. Alvarez, P.; Levine, J.D. Antihyperalgesic effect of tetrodotoxin in rat models of persistent muscle pain. Neuroscience 2015, 311, 499-507. [CrossRef] [PubMed]

11. Green, P.G.; Alvarez, P.; Levine, J.D. Topical tetrodotoxin attenuates photophobia induced by corneal injury in the rat. J. Pain 2015, 16, 881-886. [CrossRef] [PubMed]

12. Beloeil, H.; Ababneh, Z.; Chung, R.; Zurakowski, D.; Mulkern, R.V.; Berde, C.B. Effects of bupivacaine and tetrodotoxin on carrageenan-induced hind paw inflammation in rats (Part 1): Hyperalgesia, edema, and systemic cytokines. Anesthesiology 2006, 105, 128-138. [CrossRef] [PubMed]

13. Dalziel, R.G.; Bingham, S.; Sutton, D.; Grant, D.; Champion, J.M.; Dennis, S.A.; Quinn, J.P.; Bountra, C.; Mark, M.A. Allodynia in rats infected with varicella zoster virus-A small animal model for post-herpetic neuralgia. Brain Res. Rev. 2004, 46, 234-242. [CrossRef] [PubMed]

14. Takasaki, I.; Andoh, T.; Shiraki, K.; Kuraishi, Y. Allodynia and hyperalgesia induced by herpes simplex virus type-1 infection in mice. Pain 2000, 86, 95-101. [CrossRef]

15. Chen, S.R.; Pan, H.L. Effect of systemic and intrathecal gabapentin on allodynia in a new rat model of postherpetic neuralgia. Brain Res. 2005, 1042, 108-113. [CrossRef] [PubMed]

16. Li, C.Y.; Song, Y.H.; Higuera, E.S.; Luo, Z.D. Spinal dorsal horn calcium channel $\alpha_{2} \delta-1$ subunit upregulation contributes to peripheral nerve injury-induced tactile allodynia. J. Neurosci. 2004, 24, 8494-8499. [CrossRef] [PubMed]

17. Kang, Y.; Shum, F.H.K. Composition of Sodium Channel Blocking Compound. U.S. Patent 6,559,154, 6 May 2003.

18. Hagen, N.A.; Cantin, L.; Constant, J.; Haller, T.; Blaise, G.; Ong-Lam, M.; Souich, P.D.; Korz, W.; Lapointe, B. Tetrodotoxin for moderate to severe cancer-related pain: A multicentre, randomized, double-blind, placebo-controlled, parallel-design trial. Pain Res. Manag. 2017, 2017, 7212713. [CrossRef] [PubMed]

19. Nieto, F.R.; Entrena, J.M.; Cendán, C.M.; Pozo, E.D.; Vela, J.M.; Baeyens, J.M. Tetrodotoxin inhibits the development and expression of neuropathic pain induced by paclitaxel in mice. Pain 2008, 137, 520-531. [CrossRef] [PubMed]

20. Hong, B.; Chen, H.; Han, J.; Xie, Q.; He, J.; Bai, K.; Dong, Y.; Yi, R. A study of 11-[ $\left.{ }^{3} \mathrm{H}\right]$-tetrodotoxin absorption, distribution, metabolism and excretion (ADME) in adult sprague-dawley rats. Mar. Drugs 2017, 15, 159. [CrossRef] [PubMed]

21. Moore, R.A.; Straube, S.; Wiffen, P.J.; Derry, S.; Mcquay, H.J. Pregabalin for acute and chronic pain in adults. Cochrane Database Syst. Rev. 2009, 39, CD007076. [CrossRef] [PubMed]

22. Moore, R.A.; Wiffen, P.J.; Derry, S.; Mcquay, H.J. Gabapentin for Chronic Neuropathic Pain and Fibromyalgia in Adults; John Wiley \& Sons, Ltd.: Hoboken, NJ, USA, 2014; p. CD007938.

23. Nieto, F.R.; Cobos, E.J.; Tejada, M.Á.; Sánchez-Fernández, C.; González-Cano, R.; Cendán, C.M. Tetrodotoxin (TTX) as a therapeutic agent for pain. Mar. Drugs 2012, 10, 281-305. [CrossRef] [PubMed]

24. Newman, D.J.; Cragg, G.M. Marine-sourced anti-cancer and cancer pain control agents in clinical and late preclinical development+. Mar. Drugs 2014, 12, 255-278. [CrossRef] [PubMed] 
25. Hagen, N.A.; Du, S.P.; Lapointe, B.; Onglam, M.; Dubuc, B.; Walde, D.; Love, R.; Ngoc, A.H. Tetrodotoxin for moderate to severe cancer pain: A randomized, double blind, parallel design multicenter study. J. Pain Symptom Manag. 2008, 35, 420-429. [CrossRef] [PubMed]

26. Chen, S.R.; Pan, H.L. Hypersensitivity of spinothalamic tract neurons associated with diabetic neuropathic pain in rats. J. Neurophysiol. 2002, 87, 2726-2733. [CrossRef] [PubMed]

27. Etman, M.; Nada, H.; Nada, A.; Ismail, F.; Moustafa, M.; Khalil, S. In vivo evaluation of ketorolac sustained release pellets using a new HPLC method. Eur. J. Parenter. Pharm. Sci. 2010, 15, 93-97.

28. Pandey, S.; Pandey, P.; Mishra, D.; Singh, U.K. A validated stability indicating HPLC method for the determination of process-related impurities in pantoprazole bulk drug and formulations. Braz. J. Pharm. Sci. 2013, 49, 175-184. [CrossRef]

29. Freire, C.; Ferreira, P.D. Assessment of the in-vivo drug release from pellets film-coated with a dispersion of high amylose starch and ethylcellulose for potential colon delivery. J. Pharm. Pharmacol. 2010, 62, 55-61. [CrossRef] [PubMed]

30. Spanakis, M.; Niopas, I. Determination of atenolol in human plasma by HPLC with fluorescence detection: Validation and application in a pharmacokinetic study. J. Chromatogr. Sci. 2013, 51, 128-132. [CrossRef] [PubMed]

31. Yasmoto, T.; Michishita, T. Fluorometric determination of tetrodotoxin by high performance liquid chromatography. Agric. Biol. Chem. 1985, 49, 3077-3080.

32. Yotsu, M.; Endo, A.; Yasumoto, T. An improved tetrodotoxin analyzer. J. Agric. Chem. Soc. Jpn. 1989, 53, 893-895.

33. Walash, M.I.; Belal, F.; El-Enany, N.; Eid, M.; El-Shaheny, R.N. Stability-indicating HPLC method with fluorescence detection for determination of methocarbamol in tablets. Application to therapeutic drug monitoring. J. Liquid Chromatogr. Relat. Technol. 2012, 35, 2021-2041.

34. Dukić-Ott, A.; Remon, J.P.; Foreman, P.; Vervaet, C. Immediate release of poorly soluble drugs from starch-based pellets prepared via extrusion/spheronisation. Eur. J. Pharm. Biopharm. 2007, 67, 715-724. [CrossRef] [PubMed]

35. Caccavo, D.; Lamberti, G.; Cafaro, M.M.; Barba, A.A.; Kazlauske, J.; Larsson, A. Mathematical modeling of the drug release from an ensemble of coated pellets. Br. J. Pharmacol. 2017, 174, 1797-1809. [CrossRef] [PubMed]

36. Lee, M.J.; Seo, D.Y.; Lee, H.E.; Wang, I.C.; Kim, W.S.; Jeong, M.Y.; Choi, G.J. In line NIR quantification of film thickness on pharmaceutical pellets during a fluid bed coating process. Int. J. Pharm. 2011, 403, 66-72. [CrossRef] [PubMed]

37. Verstraete, G.; De Jaeghere, W.; Vercruysse, J.; Grymonpré, W.; Vanhoorne, V.; Stauffer, F.; De Beer, T.; Bezuijen, A.; Remon, J.P.; Vervaet, C. The use of partially hydrolysed polyvinyl alcohol for the production of high drug-loaded sustained release pellets via extrusion-spheronisation and coating: In vitro and in vivo evaluation. Int. J. Pharm. 2017, 517, 88-95. [CrossRef] [PubMed]

(C) 2018 by the authors. Licensee MDPI, Basel, Switzerland. This article is an open access article distributed under the terms and conditions of the Creative Commons Attribution (CC BY) license (http://creativecommons.org/licenses/by/4.0/). 